\title{
AANTEEKENINGEN OP HAMELBERGS WERKEN
}

\author{
DOOR
}

W. R. MENKMAN

J. H. J. Hamelberg heeft zich op twee wijzen verdienstelijk gemaakt; hij was de stuwende kracht in het, helaas niet lang geleefd hebbende, Geschied-, Taal-, Land- en Volkenkundig Genootschap der Nederlandsche Antillen èn de auteur van „De Nederlanders op de West-Indische Eilanden".

De meeste waarde voor de kennis der geschiedenis van onze eilanden in de Caraibische Zee heeft wel gehad zijn arbeid in het Alg. Rijksarchief te 's-Gravenhage, van 1900 en 1901; hij heeft toen een aantal documenten, op die geschiedenis betrekking hebbend, aan het licht gebracht, welke anders misschien nog heel lang in vergetelheid zouden zijn blijven sluimeren. Ook uit andere bronnen echter heeft $H$. veel verzameld, dat aan onze kennis der historie van ons eilandengebied ten goede gekomen is.

Zijn toelichtingen en commentaren op de door hem gepubliceerde of geciteerde gegevens zijn niet altijd even gelukkig en dat is niet te verwonderen. De geschiedenis onzer Nederlandsche Antillen te zien in het veel grootere verband der koloniale geschiedenis in het algemeen, de onze en die van andere naties, is niet gemakkelijk en $\mathrm{H}$. had niet veel gelegenheid gehad tot vóórstudie. De loopbaan welke hij achter den rug had, toen hij zich aan het schrijven zette, had hem niet met speciale historische onderwerpen bekend kunnen maken en in West Indië was ook in zijn tijd al heel weinig studiemateriaal te vinden.

Uit verschillende jaarverslagen van het bovengenoemde genootschap blijkt dit laatste wel zeer duidelijk. Het derde verslag (1899) behandelt o.a. de emancipatie van 1863; blijkbaar was men op Curaçao nu eerst bekend geworden met het rapport der Staatscommissie van 1853, dat toch enkele jaren daarna van de pers gekomen is. H. zelf schreef in hetzelfde jaarverslag dat hij pas het vorige jaar Van der Sterre's werk over Jan Erasmus Reining in 
handen gekregen had. In het vierde verslag vinden wij een artikel van Rector Zwijsen, die blijkbaar van onze zeegeschiedenis niet bijzonder op de hoogte was, over den aanslag der Hollanders op Porto Rico van 1625; H. voegde er aan toe een uittreksel uit de Laets Iaerlyck Verhael, welk werk hij pas (Den Haag September 1900) in de „Deventer Bibliotheek” gevonden had.

$\mathrm{Er}$ is de laatste veertig jaren heel wat verzameld en gepubliceerd over de geschiedenis der Nederlandsche Antillen, veel meer dan in een even lang tijdperk vóór dat H. zich aan den arbeid zette. Een compleet en uitvoerig werk over dit deel onzer koloniale historie evenwel is tot dusver niet verschenen en zal ook wel niet spoedig verschijnen; er is in onze wetenschappelijke wereld niet veel belangstelling voor het onderwerp in kwestie. Zoowel bij ons Hooger als bij ons Middelbaar Onderwijs beteekent koloniale geschiedenis in de eerste plaats Indische geschiedenis; de rest wordt fragmentarisch behandeld.

Intusschen, wie zich in de geschiedenis onzer activiteit in de Caraibische Zee wil verdiepen, zal altijd nog wel beginnen met Hamelbergs geschriften ter hand te nemen, ten minste voor wat betreft de zeventiende en achttiende eeuw. Het leek mij daarom nuttig deze geschriften te annoteeren en de opmerkingen en aanvullingen welke ik meende te kunnen geven aan te bieden aan de Redactie van De West-Indische Gids, het tijdschrift dat reeds zooveel bevat op het gebied der historie, ook van de Nederlandsche Antillen en ook van de meer nabij liggende tijden dan die waarop Hamelbergs werk betrekking heeft.

Ik heb mij niet bepaald tot „De Nederlanders op de West-Indische Eilanden" (I en II, met Documenten I en II), maar ook Hamelbergs andere bijdragen tot de jaarverslagen van het G., T., L. \& V. Gen. d. N. A. onder de loupe genomen. Om te verwijzen heb ik gebruik gemaakt van de afkortingen: Ned. I en D., Ned. II en D., Jaarv. I, II, III, IV, V, VI.

$\mathrm{N}$ a men van pers onen. Wanneer H. naamregisters geeft (Ned. I, Jaarv. V. en VI), volgt hij het systeem den hoofdof familienaam slechts één maal te noemen; zoo vinden wij b.v. onder Cromwell (Naamreg. Ned. I) zoowel den Lord Protector opgenomen (Ned. I, D. 57) als Richard Cromwell (Ned. I, D. 75), zijn zoon en opvolger. Af en toe zal er aanleiding zijn op deze eigenaardigheid terug te komen.

H. wijst er ergens op (Jaarv. V., Bericht) dat, ook in de acht- 
tiende eeuw nog, de spelling, zelfs van persoonsnamen, een willekeurige was. Hij had er bij kunnen voegen dat in de zeventiende eeuw vreemde namen zelfs wel vertaald werden; zoo komt bij De Laet [Iaerl. Verhael, 10de, 11de en 12de boek) een zelfde officier bij de troepen der Compagnie in Brazilië voor als Bongarson (Bongarçon) en als Goedlad (Goodlad), zoo wordt in Nederlandsche stukken de Engelsche vice admiraal Sir John Harman wel Jan Herman genoemd enz. enz.

De admiraal Pieter Adriaansz. (Ned. I, 20) was P. Adr. Ita en Pieter Adriaansen; (Ned. II, 24) de commandeur van Sint Eustatius van 1665; eerstgenoemde zal natuurlijk niet licht verward worden met Engelbert Adriaensz, den assistent op Curaçao van 1735 (Ned. I, D. 153).

De Hertog van Albe marle (Ned. I, D. 79) is niet in het Naamregister opgenomen. Er kan hier geen sprake zijn van den eersten Hertog (George Monck, de Puritein, als zeeheld bekend in onze geschiedenis van den eersten Engelschen oorlog en in 1667 First Lord of the Treasury); bedoeld moet zijn Christopher, second Duke of Albemarle, een militair, te voren Earl of Torrington, in 1682 Lord of Trade and Plantations en in 1687 gouverneur van Jamaica, waarheen de bekende Doctor Hans Sloane hem vergezelde ${ }^{1}$ ).

Lord Arlington (Ned. I, D. 72, 79, Ned. II, 25, D. 37) was Henry Bennett, first Earl of Arlington, Secretary of State onder Karel II van Engeland. Hij was gehuwd met een zuster van Willem de Nassau, Heer van Odijk $\left.{ }^{2}\right)$.

D' Avaux (Ned. I, 59) was Jean Antoine de Mesmes, Comte d' Avaux, na den vrede van Nijmegen Fransch ambassadeur in Nederland $\left.{ }^{3}\right)$.

De Baas (Ned. I, 50, 51, 53), De Bas (Jaarv. III, 62 e.v.) was Jean Charles de Baas; H. noemt hem gouverneur van Martinique, maar deze luitenant generaal van het Koninkl. leger was destijds gouverneur generaal der Fransche Antillen. In dit tijdschrift ${ }^{4}$ ) is al eens het een en ander medegedeeld over de verschillende dra-

1) Dictionary of National Biography; A voyage to the Islands of Madera, Barbados, Nieves, S. Christophers and Jamaica.... by Hans Sloane M. D., London 1707, 1725.

2) Dictionary of National Biography; De Zeeuwsche expeditie naar de West onder Cornelis Evertsen den Jonge 1672-1674 (Linschoten Vereeniging, XXX, 1928).

s) Nouv. Biogr. générale.

4) W. I. Gids, XVII, 70. 
gers van den naam De Baas (De Baasz., De Batz, De Baatz); de onze had blijkbaar in 1675 een zoon op Grenada, de achttiende eeuwsche Jean Pierre Louis zal wel tot model gediend hebben voor den held van den bekenden Engelschen roman The scarlet Pimpernel. De gouverneur van Barbados schreef 8 (18) Februari 1677 dat D' Estrées bevelhebber was in Amerika, nu ,Mons. De Baas, the old French general", overleden was ${ }^{1}$ ).

Joh. Corn. Backer, door H. Johannes Backerus genoemd (Ned. I, 95, 223), zou vóór 1647 op Curaçao zijn bediening aangevangen hebben; Prof. Knappert heeft medegedeeld dat deze leeraar reeds in 1642 op het eiland aanwezig was ${ }^{2}$ ).

De la Barre (Ned. II, 27, 28, 30, 31, D. 39, 43, 44) was volgens $\mathrm{H}$. gouverneur generaal der Fransche Westindische eilanden; hij moet zijn geweest Antoine le Fèvre de la Barre, officier der Fransche marine, gouverneur van Fr. Guyana, in 1667 luitenant generaal en 1682/1685 gouverneur van Canada ${ }^{3}$ ).

D. Baut (Ned. II, D. 19); wij vinden David Baute of Boute, in 1638 tot bewindhebber benoemd der West-Indische Compagnie, Kamer Zeeland ${ }^{4}$ ).

Adrianus van Beaumont zou volgens H. in 1663 zijn intrede gedaan hebben op Curaçao en hetzelfde jaar overleden zijn (Ned. I, 95, 223); Prof. Knappert echter schijnt aan te nemen dat deze predikant in 1659 zijn bediening had aanvaard ${ }^{5}$ ). De Laet geeft een bewindhebber in de Zeeuwsche Kamer der Compagnie Mr. Symon van Beaumont en onze dominee zal dus ook wel een Zeeuw geweest zijn ${ }^{6}$ ).

Beck, H. neemt in zijn Naamregister alle vijf de Becks, Matthias, Wilhelm, Balthazar, Mr Jacob en Abraham, tezamen op (Ned. I, div. pl., D. div. pl.). Matthias had vóór zijn Curaçaoschen tijd negentien jaar in Brazilië doorgebracht en in 1643 een verzoekschrift van den magistraat en de burgerij van Mauritsstad mede onderteekend "). Balthazar was volgens een Engelsch bericht in

1) Stewart L. Mims, Colbert's West-India Policy, London 1912; W. I. Gids, XVII, 70; Calendar of State Papers, Am. \& West Indies, 1677/ 1680 , No 48 .

2) Gedenkb. Nederland-Curaçao 1634/1934, 35 .

s) Nouv. Biogr. générale.

4) Nieuw Ned. Biogr. Wboek.

*) Gedenkb. Ned.-Cur. 38, 42.

-) Iaerl. Verh., 34.

?) W. I. Gids, XX, 207. 
Spanje opgevoed $\left.{ }^{1}\right)$; in 1691 werd aan hem gedacht als gouverneur van Tobago, onder Koerlandsch-Brandenburgsche auspiciën ${ }^{2}$ ). In 1699 zouden de Becks op Curaçao betrokken geweest zijn bij een transactie met den bekenden Capt. Kidd in zake den verkoop van door zeeroof verkregen goederen ${ }^{3}$ ).

De Vice-Directeur Beer (Ned. I, D. 76) is niet in het Naamregister opgenomen; door een schrijffout zal de naam van Matthias Beck in dezen vorm in het document in kwestie verschenen zijn, derhalve behoort in het Naamregister „D. 76” ingevoegd te worden, achter den naam Beck.

Becker (Ned. I, 17, 41, 88, 126); die van 1633 en 1634 moet de Zeeuwsche bewindhebber der West-Indische Compagnie Steven B. geweest zijn, bij De Laet te vinden ${ }^{4}$ ).

De twee Van Belles in H's Naamregister zijn de gebroeders Pedro of Pieter en Josua, wier betrekkingen tot den slavenhandel ook uit moederlandsche archivaliën blijkt ${ }^{5}$ ). Pedro is ook in de West werkzaam geweest, op Curaçao en elders; hij was op het laatst der zeventiende en in het begin der achttiende eeuw factor van de Brandenburgsche compagnie op Sint Thomas, was betrokken bij het smokkelen van slaven van daar naar Sint Kitts en bij den verkoop van gestolen goederen (zie Beck) ${ }^{6}$ ).

Belmontes of $D e$ Belmontes komen er bij H. eenige voor (Ned. I, 75 , D. 122, 154). Ten tijde van het asiento van García, zegt H., was de agent op Curaçao ,niemand minder dan Don Juan Pedro de Belmonte", doch waarom dit een zoo bijzondere persoon was, blijkt niet. De bij ons bekendste drager van dien naam was François (Francisco) Schoonenberg, de Nederlansche zaakgelastigde te Madrid, die een rol gespeeld heeft in de kwestie van het z.g. Coymans asiento; de gebroeders Isaac Nunez Belmonte (alias Manoël de Belmonte) en André de B. waren agenten van Spanje te Amsterdam en althans Manoël was mede bij den slavenhandel

1) Doc. Illustrative of the Hist. of the Slave Trade to America, ed. by Elis. Donnan, Publ. by Carnegie Inst. of Washington, 1930, I. seventeenth cent., doc., No 131 .

2) E. Seraphim, Gesch. Liv-, Est- u. Koerlands, Reval 1897.

s) W. Westergaard, The Danish West Indies, New York 1917.

•) Iaerl. Verh., 34

s) W. I. Gids, XVII, 11 e.v.; Irene A. Wright, The Coymans asiento (Bijdr. Vad. Gesch. \& Oudheidk. VIde reeks 1); Mr H. C. Hazewinkel, Een Rotterdamsche Tontine (Rott. Jaarb. 1932).

•) Doc. .... Slave Trade..... I, doc. No 119, zie vroeger; W. I. Gids, $\mathrm{XX}, 189,191$. 
betrokken ${ }^{1}$ ). De gezant Schoonenberg heet ook wel Johan Abraham de Belmonte ${ }^{2}$ ).

Van Jonathan van Beuningen gaf H. een portret (Ned. I, t.o. bl. 130), waarvan het origineel in het bezit was van den Heer H. A. van Beuningen te Utrecht. Deze laatste behoort niet tot het regentengeslacht van dien naam; Jonathan en $\mathrm{Mr}$ Jan, de Curaçaosche Van Beuningens, waren leden van een geslacht, uit Emmerik afkomstig en zeer waarschijnlijk niet verwant aan het Amsterdamsche. Mr Jan van B. was vóór zijn Curaçaoschen tijd koopman te Amsterdam ${ }^{3}$ ).

Joan Benners (Ned. II, 51), Joannes Benner (Ned. II, D. 48) en Jannes Benner (Jaarv. IV, Extract uyt de Boecken van d. Hr Lowijs houtcooper $\mathrm{Zal}$.) zijn wellicht één en dezelfde persoon.

Ch. de Courbon, Comte de B lé n a c (Ned. II, 45, 47, 48, 49, D. 46, 47; Jaarv. IV, Tobago, bijl.) komt herhaaldelijk ook elders voor in de geschiedenis onzer betrekkingen tot Tobago $\left.{ }^{4}\right)$. Hij was marineofficier en commandeerde in 1677 onder D'Estrées een groot schip, maar in hetzeifde jaar vinden wij hem zoowel als gouverneur generaal der Fransche Antillen, alsook als gouverneur van Martinique; in deze laatste kwaliteit komt hij tot 1692 voor ${ }^{5}$ ).

Bisscop (Ned. I, D. 17) was ook alweer een door De Laet genoemd bewindhebber van Kamer Zeeland, Abraham Bisschop $\left.{ }^{6}\right)$.

Adriaen Block, de schipper van het schip De Liefde, (Ned. I, D. 58, Ned. II, 13) zal wel niet dezelfde zeeman zijn die, dertig jaar eerder, genoemd wordt in de geschiedenis van Nieuw Nederland; ook niet de Adr. Martensz. Block uit de geschiedenis van Ned. Indië 7 ).

De Heer Blommaert (Ned. II, 9, D. 12) is natuurlijk Samuel B., die ook door De Laet genoemd wordt, die een rol

1) Irene A. Wright, The Coymans asiento, zie vroeger; Doc. . . . . Slave Trade...., I, doc. No 123 e.v. zie vroeger; W. I. Gids, XVII, 18; Mr H. J. Koenen, Gesch. der Joden in Ned., 183, Utrecht 1843.

2) Dr M. Wolff, De eerste vestiging der Joden te Amsterdam (Bijdr. Vad. Gesch. \& Oudheidk. IV, 9 en 10).

s) Mr R. van Beuningen van Helsdingen, De Nederlandsche Laeuw, Nov. 1916, 268.

4) W. I. Gids, XXI, XXII.

s) A. M. H. J. Stokvis, Manuel d'Histoire, Leiden 1889.

-) Iaerl. Verh., 34.

7) Mr F. Muller Fzn, Geschiedenis der Noordsche Compagnie, Utrecht 1874; Dr J. W. IJzerman, Cornelis Buysero te Bantam 1616-1618 (Linschoten Ver. 1923); Jhr Mr J. K. J. de Jonge, L. M. van Deventer, De opkomst van het Nederlandsche gezag....., II, 160, 's Gravenhage 1865; N. Ned. Biogr. Wboek. 
gespeeld heeft in de geschiedenis van Nieuw Nederland en aangaande wien Prof. Kernkamp zoo vele bijzonderheden gepubliceerd heeft ${ }^{\mathbf{1}}$ ).

Behalve de kaperkapitein Gerrit (Garest, Gerret, Gerart, Gerard) Bogaert (Bogard, Boogard, Bogert), door H. genoemd (Ned. II, 26, 28, 34, D. 40, 42, 44, 46), komen er nog meer Zeeuwen van dezen naam in onze Amerikaansche geschiedenis voor. De memorie van Artichewsky van 1637, in het archief van Van Hilte, geschreven bij vertrek uit Brazilië, spreekt van een vrijen koopman Bogaert, bij wien vivres te koop waren; Theunis Gijsbertse Bogart was in 1673 schepen van het dorp Breukelen in Nieuw Nederland; Matthijs Bogaert was omstreeks 1700 een Zeeuwsche slavenhaler (lorredraaier) ${ }^{2}$ ).

De Heer Bont (Ned. II, D. 18) komt bij De Laet niet als bewindhebber voor, maar zou misschien de Middelburgsche bewindhebber tijdens den vierden Engelschen oorlog kunnen zijn, hoewel er een groot tijdverschil is ${ }^{3}$ ).

Justus Boot wordt door $\mathrm{H}$. alleen genoemd als commandant van een Landsschip in 1782 (Ned. I, 180); dat hij bij de verovering van een Engelsch schip geassisteerd werd door twee Curaçaosche commissievaarders, wordt door De Jonge niet vermeld. Volgens dezen laatste was de ,Surprise” zelf een kaper; aangaande Boots aandeel in het geval van de „Machtelyne” spreekt H. niet $\left.{ }^{4}\right)$.

De Heer Boursen (Ned. I, D. 32) moet geweest zijn de Amsterdamsche bewindhebber der West-Indische Compagnie Jaques Beurse, door De Laet genoemd ${ }^{5}$ ).

Brugmans komen er vele voor in de Curaçaosche geschiedenis (Ned. I, 189, D. 122, 125, 155; Jaarv. III, 135; Jaarv. V, Extr. trouwboek 1714-1722); ook buiten die welke H. noemt vinden wij er nog één in 1635. Van den Brugman die in 1795 bij het slavenoproer sneuvelde geeft $\mathrm{H}$. de voornamen, Pieter Beek $\left.{ }^{6}\right)$.

De schout bij nacht Van Bylandt (Ned. I, 187, 188, D.

1) Iaerl. Verh., 32; Zweedsche Archivalia (Bijdr. en Meded. Hist. Gen., XXIX, 1908); David Pietersz. de Vries, Korte Historiael (H. T. Colenbrander, Linschoten Ver., III 1911).

${ }^{2}$ Kroniek Hist. Gen. XXV, 1869, 5de serie; De Zeeuwsche expeditie naar de West, zie vroeger.; L. Knappert, Gesch. v. d. Ned. BovenwEil. i. d. achtt. eeuw, 's Hage 1932.

s) Iaerl. Verh., 32/37; Jhr J. C. de Jonge, Gesch. v. h. Ned. Zeewezen.

4) De Jonge, zie 3).

s) Iaer. Verh., 32.

•) W. I. Gids, XVII, 211; A. T. Brusse, Curaçao en zijn bewoners, Curaçao 1882 . 
184, 186) was Lodewijk Graaf van B., later ook bekend in de geschiedenis van Sint Eustatius $\left.{ }^{1}\right)$.

Jan Claesz. van Campen (Ned. I, 37, 221, D. 35, 36, 215); of hij de commandeur was die Sint Maarten op 1 Juli 1633 aan de Spanjaarden moest overgeven en of hij op Curaçao Van Walbeeck opvolgde, heb ook ik niet vermogen vast te stellen. In ieder geval was hij in 1635 op Curaçao en werd hij in 1642 directeur van Curaçao genoemd ${ }^{2}$ ).

James Hay, first Earl of Carlisle (Ned. II, 9, 11, D. 8, 9) verkreeg op 2 Juli 1627 patentbrieven voor een reeks van eilanden in West Indië (waaronder Sint Eustatius, en Sint Maarten) ,\& omes alias insulas sive insululas infra viginti gradus linie equinoctialis a borea", om die te bezitten op denzelfden voet als de bisschop van Durham zijn bisdom of paltsgraafschap bezat en verder met alle prerogatieven van een kapitein generaal der Engelsche Kroon ${ }^{3}$ ).

De Spaansche priester, dien de onzen in 1634 op Curaçao aantroffen (Ned. I, 29), heette Salvador de Carmona ${ }^{4}$ ).

Over Jacques Cassard (Ned. I, 119/121, 127, D. 114, 115, 178) bestaat nogal wat litteratuur; Marc. Elder gaf zijn levensbeschrijving ${ }^{5}$ ). $\mathrm{H}$. heeft Cassards aanslag op Curaçao met zeker leedwezen beschreven en is aan het optreden der Fransche kapers op de Bovenwindsche Eilanden niet meer toe gekomen. Eenige op Curaçao aangetroffen stukken betreffende het geval van 1713 zijn (door Hamelberg?) afzonderlijk gepubliceerd (Jaarv. I, Bijlagen, A.) en Mr. B. De Ga a y Fortman gaf in dit tijdschrift het relaas er van, van een ooggetuige ${ }^{6}$ ).

Charles Chabert, de civiele gouverneur van Sint Eustatius en Saba (1782/1784) van wege Lodewijk XVI $\left.{ }^{7}\right)$, was volgens $H$. een Statiaan (Jaarv. IV, 139); waarop deze bijzonderheid berust is mij niet gebleken. De Charles Chabert die in 1739 op Sint Eustatius in het huwelijk trad, was geboortig van Guadeloupe en aldaar

1) W. I. Gids, XV, 23 e.v.

2) W. I. Gids, XVII, 198.

s) James A. Williamson, The Caribbees under the proprietary patents, London 1926.

4) Rapport Van Walbeeck, Alg. Rijksarchief, Br. en Pap. van Braz.

(W. I. C. oud, 50).

s) Jacques Cassard, Corsaire de Nantes.

-) W. I. Gids, VI, 241 e.v.

7) A. H. Bisschop Grevelink, Beschrijving van Sint Eustatius (Bijdr. tot de kennis der Nederl. en Vreemde Koloniën, 1846). 
woonachtig (Jaarv. VI, Genealogie); deze kan de vader geweest zijn.

Dr Diego Alvarez Chanca (Ned. II, 5, D. 3), was een Seviliaan, die op voorspraak van Ferdinand en Isabella door Columbus als „zuragvano" werd aangenomen voor de tweede reis; Chanca's brief is een der weinige als authentiek beschouwde beschrijvingen van deelnemers aan de eerste reizen naar de nieuwe wereld ${ }^{1}$ ).

$\mathrm{H}$. heeft niet kunnen vinden waarom de overgave van Sint Eustatius door den luit. kolonel James Cockburn aan den markies de Bouillé ,discreditable” geweest zou zijn (Jaarv. IV, 138). Prof. Knappert echter verwijst naar het gerechtelijk onderzoek ter zake dat (later?) ook aan $\mathrm{H}$. bekend moet zijn geweest ${ }^{2}$ ). Het oordeel over Cockburns gedragingen op Sint Eustatius, na de verovering door Rodney, is over het geheel ongunstig ${ }^{3}$ ). De Bouillé komt als gouverneur van Martinique voor van 1777 tot $1782^{4}$ ).

Sir Christopher Codrington is de stichter van Codrington College op Barbados, waar hij geboren was en in 1710 overleed. Zijn vader, eveneens Christopher geheeten, was de Codrington van 1693 (Ned. 53, 54, D. 49). H. noemt hem gouverneur der Engelsche benedenwindsche eilanden en hij is inderdaad captain general and commander in chief of the Leeward Islands geweest; in 1699 echter werd hij nog kolonel genoemd. Hij schreef in dat jaar aan de Council of Trade and Plantations o.a. „Christianity does not alter the conditions of men, nor destroy the right of tenure by which slaves are held" ${ }^{5}$ ).

De Heer Coenradus (Ned. I, 42) komt bij De Laet niet voor, tenzij hij dezelfde was als Alberts Coenraad Burgh, schepen, bewindhebber Kamer Amsterdam ${ }^{6}$ ).

Inderdaad had Pieter Constant (Ned. I, 53, D. 94, 98) Tobago overgegeven op voorwaarde dat hij en de andere ambtenaren vrijen aftocht zouden verkrijgen naar Curaçao $^{7}$ ). Hij zou derhalve aan den oorlog tegen Engeland wel geen deel meer hebben mogen nemen, doch of de Franschen zich op de capitulatievoorwaarden van Tobago konden beroepen, lijkt niet zeker.

1) Select documents illustrating the four voyages of Columbus, Cecil Jane, Hakluyt Soc., London 1930.

2) Knappert, Gesch. Ned. Bovenw. Eil., zie vroeger; Dict. of Nat. Biogr.

s) Corn. de Jong, Reize n.d. Caraib. Eil., Haarlem 1807.

*) Stokvis, Manuel, zie vroeger.

- Calendar of State Papers, Am \& W. I., 1699, 628.

-) Iaerl. Verh., 32.

?) Calendar of State Papers, Am. \& W. I., 1669/1674, 995. 
Van David Coppin lezen wij dat hij in 1648 luitenant der burgerij was (Ned. II, D. 30, 32), waarschijnlijk op Sint Eustatius. Dezelfde Zeeuwsche (Middelburgsche) naam (Copin, Coppijn) komt ook voor in de geschiedenis van Tobago ${ }^{1}$ ).

Confrater B. Courten (Ned. I, D. 13) moet geweest zijn Pieter Boudaen Courten, door De Laet genoemd als bewindhebber in de Kamer Zeeland en oomzegger van Sir William en Sir Peter Courteen ${ }^{2}$ ).

Coymans, Cooijmans, Koeymans, Koeyman, Coeyman, zullen wel verschillende schrijfwijzen zijn van denzelfden geslachtsnaam (Ned. I, 74, 75, 131, D. 73, 125, 156; Jaarv. III, 90; Jaarv. V, Extract Trouwboek Curaçao 1714/1722). De Coymansen waren geparenteerd aan de Courtens, door de huwelijken der zoons van Mr P. Boudaen Courten ${ }^{2}$ ).

Een Antwerpsche Coymans was in 1594 gevestigd te Palma op de Canarische Eilanden ${ }^{3}$ ), een Thomas Coymans voer met De Houtman naar Indië, Isaac Coymans was eerst in dienst van de West-Indische Compagnie, later een der oprichters van de Deensch-Afrikaansche compagnie $\left.{ }^{4}\right)$. Door aanhuwelijking met Hollandsche en Zeeuwsche koopmansgeslachten (Courten, Reynst Blommaert, Trip, Deutz, Lampsins) behoorden de Coymansen tot die betrekkelijk kleine groep van Nederlandsche ondernemers, die te zamen de overzeesche en internationale zaken in handen had'?en ${ }^{5}$.

Een Amsterdamsche Coymans was in het midden der zeventiende eeuw bekend als bankier, koopman en speculant, o.a. betrokken bij het plan van een Venetiaansch kantoor van lijfrenten ${ }^{6}$ ); in 1684 noemde de gouverneur van Jamaica de Amsterdamsche firma Coymans de grootste handelsonderneming van Europa ${ }^{7}$ ).

Dat Balthazar Coymans te Cadix Ridder, Heer van Streefkerke en schepen der stad Amsterdam was, is herhaaldelijk van H. na-

1) W. I. Gids, XXI, 373, XXII, 108.

2) Iaerl. Verh., 34; W. I. Gids, X, 529.

3) Dr J. Denucé, Afrika i.d. XVIde eeuw en de handel van Antwerpen, 1937.

4) De Jonge, Opkomst, zie vroeger; N. de Roever, Twee concurrenten v.d. W. I. Comp. (Oud Holland, 1889).

s) G. W. Kernkamp, Z weedsche Archivalia, zie vroeger; W. I. Gids, IX, 157,158 .

- Dr P. Geyl, Troepen lichten en schepen huren in de dagen van Fred. Hendrik (Bijdr. Vad. Gesch. en Oudheidk., V, 5).

${ }^{2}$ ) Doc. ...Slave Trade...., seventh. cent., doc. No. 119, zie vroeger. 
geschreven, o.a. door $\mathrm{mij}^{1}{ }^{1}$ ); toch is dit bij nader inzien wellicht niet juist. Elias ${ }^{2}$ ) geeft twee Balthazars Coymans, die denzelfden titel voerden, doch waarvan de oudste reeds in 1659 overleed; de tweede woonde te Haarlem en overleed aldaar in 1690.

De Balth. Coymans van het asiento echter deed zaken te Cadix en overleed aldaar 8 November $1686^{3}$ ); Miss Wright heeft allerlei bijzonderheden over zijn leven en werken in Spanje verzameld.

De Coymansen die in 1651 tegen de navigation law protesteerden, waren natuurlijk de Amsterdamsche kooplieden; de Balth. Coymans die op Curaçao bijdroeg in de brandschatting van Cassard kan dezelfde geweest zijn die in 1718 lid van den Curaçaoschen raad werd, misschien ook dezelfde die in 1735 voor hoofdgeld en familiegeld aangeslagen werd op Curaçao, terwijl de Balth. Coeyman die in 1722 op Sint Eustatius als getuige bij een huwelijk optrad, allicht een ander was.

De Koeymans te Amsterdam, volgens Curaçaosch archief Koeyman, genoemd in de geschiedenis van Jan Erasmus Reining, moet een lid geweest zijn van de firma die bij het asiento betrokken was.

Abraham Crijssen wordt door H. maar even genoemd (Ned. II, 38); hij speelt in onze geschiedenis der Nederlandsche Antillen alleen in zoover een rol dat hij in den tweeden Engelschen oorlog Tobago weder onder ons gezag bracht. Bijzonderheden aangaande dezen Zeeuwschen bevelhebber zijn op verschillende plaatsen te vinden; de kaper Teun Crijnssen van den derden Engelschen oor$\log$ was wellicht zijn zoon $\left.{ }^{4}\right)$.

De Cussac (Ned. II, 10, D. 12, 13) was François de Rotondy, Sieur de Cahusac, die in 1629 kolonisten op Sint Eustatius zou gebracht hebben en in 1635 aldaar, als commandant van een door Richelieu naar de Antillen uitgezonden eskader, het fort zou gebouwd hebben, dat later door de onzen in bezit genomen werd, toen de Franschen hun belangstelling voor het eiland blijkbaar verloren hadden ${ }^{5}$ ).

Jan Doncker (Ned. I, 45, 47, 50/55, 60, 65, 73, 79, 85, 88, 93, 96, 106, 147, 221, 223, D. 91/93; Jaarv. III, 89) wordt door H. één

1) W. I. Gids, XII, 13.

2) Joh. E. Elias, De Vroedsch. v. Amsterdam, II, 672, 763, Haarlem 1905.

3) The Coymans asiento, zie vroeger; W. I. Gids, XII, 20.

4 Enc. v. Ned. W. I.; F. E. Mulert in Bijdr. Vad. Gesch. en Oudheidk., V, 5; De Zeeuwsche expeditie naar de West, zie vroeger.

s) Williamson, The Caribbees, zie vroeger; Père Du Tertre, Hist. generale des Antilles habitées par les François, traité III, chap. II, par. 10, Paris 1667. 
maal Joan D. genoemd. De Baas, die hem kende als koopman (op Saint Christophe?) noemde hem Doukre ${ }^{1}$ ). Doncker bleef inderdaad na zijn aftreden als directeur op Curaçao gevestigd en hij zette er ook zijn zaken voort; aan het Coymans asiento leverde hij scheepsruimte voor het vervoeren van slaven naar de kust ${ }^{2}$ ). Sir Wm Stapleton schreef in 1684 aan Doncker, of liever hij adresseerde zijn brief aan de belanghebbenden bij Tortola aan D., maar er blijkt niet of deze laatste toen nog op Curaçao, of reeds in Nederland gevestigd was ${ }^{3}$ ).

Jan Doncker mag natuurlijk niet verward worden met Jan Sijmonsz. Doncker, van Sint Eustatius, Compagnies chirurgijn, kapitein der burgerij en raadslid aldaar (Ned. I, 60; Ned. II, 51, 52, 54, 58, D. 48, 50, 52; Jaarv. IV, Extract uyt de Boecken van d. Hr Lowijs houtcooper); over hem en zijn nageslacht lezen wij nog veel bij Knappert ${ }^{4}$ ). Het was ten huize van de familie Doncker dat Rodney na den overval zijn intrek nam en zich te goed deed, zooals de kwartiermeester generaal Cockburn zich breed maakte bij de familie Texier ${ }^{5}$ ).

D'erville, Dorvilliers, D'orvilliers, Dornilie (Ned. II, 27, 31, D. $39,43)$ zijn wellicht verschillende namen voor denzelfden Franschen officier. Van 1700 af vinden wij verschillende D'Orvilliers als gouverneurs van Fransch Guyana, alsmede een admiraal van dien naam ${ }^{6}$ ).

Kapitein Donge (Jaarv. IV. Tobago, bijlage II) was de kapitein (of majoor) Van Dongen, door De Jonge genoemd als de commandant der landingstroepen op de expeditie van Binckes ${ }^{7}$ ).

De Heer Duvelaar (Ned. I, D. 15) zal wel geweest zijn Pieter Joosten Duyvelaer, bij De Laet voorkomend als bewindhebber in de Kamer van Zeeland ${ }^{\mathbf{8}}$ ).

De Heer Elfsdyck (Ned. I, D. 41) was de door De Laet genoemde Zeeuwsche bewindhebber Corn. Claesz. Elfsdijck ${ }^{9}$ ).

d'Esuambuc (Ned. II, 8) was Pierre Belain d'Esnambuc, een vrijbuiter van Dieppe, wiens eerste komst op Sint Christoffel waarschijnlijk in verband stond met een aan zijn schepen over-

1) Mims, Colbert's West-India Policy, zie vroeger.

2) W. I. Gids, XVII, 24.

3) Calendar of State Papers, Am. \& W. I., 1681/1685, 1527.

๑) Gesch. Ned. Bovenw. Eilanden, zie vroeger.

s) Corn. de Jong, Reize, zie vroeger.

-) Stokvis, Manuel, zie vroeger; Nouv. Biog. générale.

') Gesch. v.h. Ned. Zeew., zie vroeger.

s) Iaerl. Verh., 34

•) Idem, 34 . 
komen ongeval. David Pietersz. de Vries vond hem in het laatst van 1634 nog met het gezag op het Fransche deel van het eiland bekleed ${ }^{\mathbf{1}}$.

H. citeert ergens een Engelsch schrijver, C. Washington Eves (Jaarv. II, 123); waarschijnlijk heeft onze Curaçaosche kroniekschrijver geraadpleegd de Catalogue of the Library of the Royal Colonial Institute 1886 (London 1886), geredigeerd door Eves.

De omvangrijkheid der nalatenschap van Isaac Faesch (Ned. I, 177) wordt nog eens extra aangetoond door den inventaris zijner lijfsgoederen (Jaarv. II, Bijlaag D.).

De Garcia (Ned. I, 75, D. 123) die eenigen tijd, maar niet tot 1689 , houder was van het Spaansche slavenasiento, gefinancierd door de Coymans' te Amsterdam, was de Portugees Antonio G. ${ }^{2}$ ).

H. noemt Lord Germain (Jaarv. IV, 117) gouverneur generaal der Engelsche Westindische eilanden; de biographie van George Sackville, Lord Germain, zegt evenwel niet dat deze ooit in de West gediend zou hebben. Hij was tot 1779 Lord Commissioner of Trade and Plantations en later, tot 1782, Secretary of State for the Colonies ${ }^{3}$ ). Die van 1794 was dus niet de eerste Engelsche minister van Koloniën $\left.{ }^{4}\right)$.

Pierre le Grand (Ned. I, 21-23, 26-28, 37, D. 17, 24, 25, 32, 34, $35,41,43,44)$ was natuurlijk een ander dan de Fransche flibustier van dien naam (bij ons Pieter de Groot), van Dieppe ${ }^{5}$ ); onze majoor komt in de geschiedenis van Nederlandsch Brazilië herhaaldelijk voor, zoowel na als voor zijn Curaçaoschen tijd.

Als kapitein en als majoor treffen wij Le Grand voortdurend aan in de geschiedenis der krijgsverrichtingen in Brazilië, van April 1631 tot en met 7 April 1633; daarna (voorloopig) niet meer. Op 22 April van laatstgenoemd jaar repatrieerden van Brazilië een 250 tal soldaten, met de flotille onder commando van Jan Jansz. van Hoorn, welke scheepsmacht echter niet regelrecht, doch via de Caraibische Zee en Centraal Amerika thuisvoer, onderweg tegen den vijand opereerende. Het is mogelijk - en zelfs waarschijnlijk - dat met deze gelegenheid ook Le Grand ging en

1) V. T. Harlow, Colonising expeditions to the West Indies and Guiana 1623-1667, Hakluyt Soc. 2nd series LVI, 1924; Williamson, The Carribbees, zie vroeger; Korte Hist., zie vroeger.

$\left.{ }^{2}\right)$ Irene A. Wright, The Coymans asiento, zie vroeger; Doc. .. Slave Trade...., seventeenth cent., Introd., zie vroeger; Mr Dr S. van Brakel, Bescheiden over den slavenh. (Ec.-Hist. Jaarb. IV).

s) Dict. of Nat. Biogr.

4) W. Gids, XVII, 324

s) W. I. Gids, XVII, $86 / 87$. 
dat hij de bovengenoemde soldaten commandeerde; Jan Jansz. had ook een chaloupe, of jacht genaamd Nachtegael onder zijn bevelen. Dat echter Le Grand commandant was der soldaten ingescheept op het eskader dat in 1633 naar Brazilië zou zijn uitgeloopen, zooals $\mathrm{H}$. meende gevonden te hebben, is niet mogelijk, zooals uit bovenstaande gegevens blijkt; van een eskader in dat jaar is niets bekend, het Amsterdamsche scheepje de Nachtegael (een jacht?) liep 28 Januari van genoemd jaar uit en kwam 11 April in Brazilië aan, alles volgens De Laet ${ }^{\mathbf{1}}$ ).

De Fransche vrijbuiter Sieur de Grammont (Ned. I, 62) leverde aan D'Estrées een hulpmacht tegen de Spanjaarden, onze bondgenooten in den oorlog van 1672; de vrede van Nijmegen (1678) maakte niet direct een einde aan den Fransch-Spaanschen oorlog en De Grammont verontrustte nog de Spaansche vestigingen aan de Costa Firme en aan het meer van Maracaibo. Hij plunderde nog in 1680 Laguaira en was in 1684 luitenant gouverneur van Saint Domingue. De Nederlandsche vrijbuiters Laurens de Graaf en Nikolaas van Hoorn waren in 1682 zijn medewerkers ${ }^{2}$ ).

De naam Grillo (Ned. I, 72, 73) wordt door H. ook wel geschreven De Grilies (Jaarv. III, 62). Grillo is een Spaansche (en ook een Portugeesche) naam (krekel) en Domingo G. zal wel een Spanjaard geweest zijn; in de zestiende en zeventiende eeuw werd in Spanje het slavenasiento in den regel slechts verleend aan onderdanen van den Koning. Tezamen met Ambrosio Lomelino vormde hij een combinatie, maar geen firma en zeker geen Curaçaosche firma, zooals $\mathrm{H}$. meent; Lomelino is een Italiaansche naam en de houders van het asiento werden bij ons en bij de Engelschen meestal als ,de Genueezen” aangeduid.

Voor Van Groenewegen, zie onder Warner.

De Heer Gijselingh (Ned. II, D. 20, 21) was de Zeeuwsche bewindhebber Johan Gijsselingh, door De Laet genoemd ${ }^{3}$ ).

Capt. Johan Harman (Ned. II, 23) was de latere vice admiraal Sir John Harman, die in den tweeden Engelschen oorlog Suriname voor korten tijd heroverd heeft ${ }^{4}$ ).

Het is mij niet gelukt iets te weten te komen aangaande de af-

1) Gedenkb. Nederland - Curaçao, 31/33, zie vroeger; Iaerl. Verh., $235,236,289,300,320,322,324,325 / 330,355,357,370$.

2) A. P. Newton, The European nations in the West Indies 14931688, The Pioneer histories, 1933.

3) Iaerl. Verh., 34, 296, passim.

4) J.C.M.Warnsinck, Abraham Crijnssen, Amsterdam 1936; Harlow, Col. expeditions, zie vroeger. 
stamming van den Curaçaoschen secretaris en notaris Willem Heldewier (Ned. I, 75, 105, D. 104, 120, 139) van het eerste kwart der achttiende eeuw. Noch Nederland's Adelsboek, noch Nederland's Patriciaat zeggen iets aangaande een Willem H. Zie verder onder Vignon.

Van De Laet neemt H. over dat Boudewijn Hendricksz (Ned. I, 19) burgemeester was van Edam; in de Kamer van het Noorder kwartier hadden echter twee burgemeesters van Edam zitting, Boudewijn Heynsz. en Marten Boudewijnsz. De eerstgenoemde zal wel onze ,generaal" geweest zijn op den tocht van 1625/1626. Van den mislukten aanslag op Porto Rico heeft Pater Zwijsen een verhaal gedaan (Jaarv. IV, De Hollanders op Porto-Rico in 1625), dat niet van historische waarde is; $H$. heeft daarop toen laten volgen wat De Laet er van geschreven heeft ${ }^{1}$ ). Van den aftocht der onzen bezat het Prado Museum te Madrid een schilderij, van den contemporairen Spaanschen schilder Félix, wel een bewijs dat men in Spanje de krijgsverrichtingen der West-Indischen Compagnie van groote beteekenis achtte, krijgsverrichtingen waarvan hier te lande het groote publiek niet veel meer onthouden heeft dan dat Piet Heyn in 1628 de Zilvervloot veroverde.

In 1937 enceneerde het (Amerikaansche) garnizoen van Porto Rico een historisch spel, tot onderwerp hebbend den aanslag op El Morro de San Felipe, het kasteel van San Juan de Porto Rico, door de Hollanders in 1625. Volgens een bericht in een Nederlandsch blad was er enorme belangstelling bij de plaatselijke bevolking; het programma gaf zelfs, vrijwel nauwkeurig gespeld, de namen der voornaamste figuren in den strijd, Hendricksz, Molckman, Jan Stapels, Thyene, Useels, Don Juan de Haro, Amezquita.

De Statiaansche fiscaal Van der Hoeven (Jaarv. IV, 135) was de Rotterdammer Mr Johannes Lambertus ter Hoeven ${ }^{2}$ ); hij zou zich, na den overval van 1781, aan boord van de Torbay niet bijster flink gedragen hebben en repatrieerde, tegelijk met den commandeur, en zoo vele anderen, met een vloot van ongeveer honderd schepen, onder geleide van de Vigilante. Men moest eenigen tijd in Engeland vertoeven, alvorens paspoort te verkrijgen voor Holland. Zoowel De Graaff als Ter Hoeven zijn naar Sint Eustatius teruggekeerd, de eerste als ambteloos burger, de laatste wederom als fiscaal, ditmaal tevens raadslid ${ }^{2}$ ).

Sir Robert Holmes (Ned. II, 19, 20, 21, D. 36) had inderdaad misschien voor wat hij, voordat de tweede Engelsche oorlog wer-

1) Iaerl. Verh., 36, 59/65.

2) W. I. Gids, XV, 33 e.v., 364 ; Corn. de Jong, Reize, zie vroeger. 
kelijk uitbrak, tegenover de onzen bedreven heeft, geen opdracht van Karel II; Holmes heeft in 1665 eenigen tijd in de Tower gevangen gezeten, wegens deze euveldaden, maar dit heeft hem niet belet later een groote carrière te maken bij de Marine ${ }^{1}$ ).

De Heer ambassadeur Joachimy (Ned. I, D. 8) was de Zeeuw Albert Joachimy, pensionaris van Goes, die de Republiek in verscheidene landen vertegenwoordigd heeft ${ }^{2}$ ).

Van Corn. Cornelisz. Jol (Ned. I, D. 33, 34, 47), bijgenaamd Houtebeen (Pie de Palo), bezitten wij nu eindelijk een goede levensbeschrijving, van de hand van Prof. Warnsinck ${ }^{3}$ ). Indertijd teekende ik aan dat Jol niet in November 1636 in Patria terug geweest kon zijn, wat echter onjuist was; de Heer Warnsinck had De Laet wèl goed gelezen, maar ik niet ${ }^{4}$ ).

Père Labat (Ned. II, 50) heeft ons ook nog verteld, dat er op het eind der zeventiende eeuw korten tijd een Capucijner missie op Sint Maarten gewerkt heeft (Jaarv. II, 134); het lijkt niet zeker of dit feit met de geschiedenis van het kerkelijk leven op het Nederlandsche deel des eilands iets te maken heeft.

Van Joannes de Laet (Ned. I, 18-23, 25, 30, 37, D. 5, 16, 28, 29, 40 , Ned. II, 7) vertelt H. dat deze bewindhebber der Compagnie zelf een reis naar de West gemaakt zou hebben, een bijzonderheid welke men elders niet vermeld of bevestigd vindt. L'Honoré Naber ${ }^{5}$ ) geeft een oordeel over De Laet als wetenschappelijk werker en vermeldt dat de uitgave van het Iaerlyck Verhael aanvankelijk acht gulden kostte; ik vond dat in 1644, het jaar waarin het werk verscheen, twintig gulden betaald werd voor twee exemplaren ${ }^{6}$ ). De Laet was mededeelhebber in het patroonschap Renselaerswijck in Nieuw Nederland ${ }^{7}$ ).

Dat de Lamonts, Isaac (Ned. I, 103, 107, 116, 226, D. 124, 162, II, 55, 58, D. 51, 52) en Willem (Ned. I, D. 118, 162; Jaarv. I, Bijl. B.) broeders waren, leeren wij uit Knapperts werk ${ }^{8}$ ).

De naam van Abraham Langford (Ned. I, D. 79) ontbreekt in het Naamregister.

Een oudere Van Liebergen dan Nicolaes (Ned. I, 60-69, 85,

$\left.{ }^{1}\right)$ N. Japikse, De verwikkelingen tusschen de Republ. en Engeland van 1660-1665, 165/459, Diss. 1900; Dict. of Nat. Biogr.

2) N. Ned. Biogr. Woordenb.

s) Iaerl. Verh. IV, Linschoten Ver. XI, 1937.

4) W. I. Gids, XX, 203.

s) Iaerl. Verh. I, Linsch. Ver. XXIV, 1931.

-) Archief v. Kerk. en Wereldl. Gesch., dl. II.

7) De Zeeuwsche expeditie naar de West, zie vroeger.

*) Gesch. Ned. Bovenw. Eil., zie vroeger. 
87-89, 92, 221, 226, D. 101, 117), n.1. Daniel, wordt door De Laet ook reeds als Amsterdamsch bewindhebber genoemd ${ }^{1}$ ). Een Arnoudt van Lybergen behoorde tot hen die, na het placaat van 27 Maart 1614, octrooi vroegen voor reizen naar Noord Amerika (Nieuw Nederland) ${ }^{2}$ ).

Confrater Louijssen (Ned. I, D. 42) kan de Zeeuwsche bewindhebber Jan Louijs van De Laet geweest zijn ${ }^{3}$ ); de Louisz.'s zijn betrokken geweest bij koloniale aangelegenheden tot laat in de achttiende eeuw toe, o.a. als kooplieden op Afrika en Sint Eustatius ${ }^{4}$ ) en in het rapport der Staatscommissie van 1853 in zake de emancipatie der slaven komt een J. Louissen voor als eigenaar van slaven (in Suriname?).

Lomelino (Ned. I, 47, 48, 72, 73, D. 92) is een Italiaansche naam (zie Grillo), ook wel geschreven Lomelini, Lomellini, of Lomellino; het is die eener Genueesche familie, oorspronkelijk uit Lombardije afkomstig, bekend in de diplomatieke wereld, maar ook in die van het bankwezen, den handel, de zeevaart en de parelvisscherij ${ }^{5}$ ). Het is dus duidelijk waarom het asiento van 1662 dat der Genueezen genoemd werd; Ambrosio Lomelino zal de voornaamste figuur geweest zijn in de combinatie. H. vertelt dat Francisco L., zeer waarschijnlijk een familielid, in 1673 agent van het asiento op Curaçao was en hulp verleende bij de verdediging tegen de Franschen; Ambrosio schijnt ook in de West geweest en daar in 1668 overleden te zijn $\left.{ }^{6}\right)$.

Henri en Robert de Lonvilliers (Ned. II, D. 30, 32), van 1648, zijn allicht verwanten geweest van Poincy (zie aldaar en ook Ned. II, 16).

De Heer De Maecht (Ned. II, D. 18) wordt door De Laet niet genoemd; wij weten alleen dat deze naam die is van een Zeeuwsch geslacht ${ }^{7}$ ).

H. noemt, in verband met het geval van het slavenschip De Koning Balthazar zekeren Johan François Massias als agent van Spanje te Amsterdam (Jaarv. III, 90/91); reeds in 1657, dus een dertigtal jaren eerder, sloot de West-Indische Compagnie een contract met den Amsterdamschen koopman Henrico Matthias, no-

\footnotetext{
1) Iaerl. Verh., 33.

2) Bijdr. tot de gesch. onzer kolonisatie in Noord Amerika (De Gids 1848).

s) Iaer. Ver., 35 .

4) W. I. Gids, XV, 38, 328.

s) Enciclopedia Italiana; Du Tertre, Hist. gen., traité IV, chap. I, par. I, zie vroeger.

-) Doc. ...Slave Trade...., I, Introd., zie vroeger.

7) Iaerl. Ver., 32, 37; Van der Aa, Ned. Biogr. Woordenb. 
pens een lading slaven naar Curaçao, zeer waarschijnlijk de eerste stap om het eiland tot een slavendepôt voor de Spaansche koloniën te maken ${ }^{1}$ ).

H. noemt Juan Matthios, met zijn twaalf kinderen (Ned. I, 30), de vorige gouverneur van Curaçao (1634); Van Walbeeck evenwel kent hem geen functie toe en wij kunnen alleen aannemen dat hij een Spanjaard was ${ }^{2}$ ). De Spaansche stukken spreken van hem als van den mayor domo en justicia mayor, terwijl zij ook een $\mathrm{Cu}$ raçaoschen Indiaan Juan Mateo noemen ${ }^{3}$ ). Van Grol houdt Juan Matheus (Matthias, Matheos) voor een opzichter van het beestiaal ${ }^{4}$.

Vice admiraal Meppel (Van Meppelen), van de vloot van De Ruyter (Ned. II, 21, D. 37) was Jan Cornelisz. van Meppel, door De Jonge op diverse plaatsen genoemd ${ }^{5}$ ).

Dat Gerard de Mepsche (Ned. I, 215) door den directeur Van Collen tot waarnemend kapitein luitenant der militie van Curaçao benoemd werd en nog in 1716 deze functie vervulde (Jaarv. V, Extract trouwboek 1714/1722), was toch misschien niet zoo heel vreemd. De Mepsche was een ,,jonker" en had in Nederland een officiersrang bekleed, zooals Prof. Knappert mededeelt ${ }^{6}$ ).

„Governor Meynell, who died" (Jaarv. IV, 140) is niet bekend; Edm. Burke bedoelde waarschijnlijk Pieter Runnels, den bejaarden kapitein der burgerij op Sint Eustatius, die na Rodney's overval van 1781 eenigen tijd aan boord van de Sandwich moest vertoeven en aldaar overleed ${ }^{7}$ ).

Wie $C$. Mings was (Ned. I, D. 72), wiens activiteit na 1660 voor de Engelschen de zaak van den slavenhandel bij de Spanjaarden bedierf, heb ik niet kunnen vinden.

Dat de onzen in 1634 Balthasar de Montero tot hoofd der Indianen aanstelden (Ned. I, 30, 32) heeft H. uit De Laet overgenomen ${ }^{8}$ ); bij de Spanjaarden was „Don” Pedro Ortiz ,cacique” der inboorlingen geweest $\left.{ }^{9}\right)$. Van Walbeeck onderhield blijkbaar betrekkingen met zekeren Juan Mestizo (een kleurling dus), die

1) Doc. ..Slave Trade...., I, doc. No. 30, zie vroeger.

2) Rapport, zie vroeger.

3) W. I. Gids, XVII, 199.

4) Idem, 211.

s) Gesch. v.h. Ned. Zeew., zie vroeger.

- Gesch. Ned. Bovenw. Eil., zie vroeger.

7) C. de Jong, Reize, zie vroeger.

s) Iaerl. Verh., 436 .

•) W. I. Gids, XVII, 199. 
de geschiedenis van Curaçao onder Spaansch bewind goed gekend schijnt te hebben ${ }^{1}$ ).

De namen Mojaard en Mooij komen bij H. ettelijke malen voor (Ned. I, D. 118, 121, 129; Jaarv. VI, Genealogie); een Daniël Mooy woonde blijkbaar in 1686 op Tortola ${ }^{2}$ ), zooals wij meer dezelfde namen tegenkomen in de geschiedenis van verschillende Nederlandsche Westindische koloniën. Een Curaçaosche Moyart wordt genoemd als betrokken bij den verkoop van Capt. Kidds plunder, tezamen met Van Belle en de Becks ${ }^{3}$ ).

Edward Morgan (Ned. II, 23, 24) was natuurlijk n i e t „de beruchte vrijbuiter", dat was Henry (later Sir Henry) Morgan 4). Edward, de oom, die in 1665, bij den aanslag op Sint Eustatius, kwam te overlijden, viel niet ,by any wound, but being ancient and corpulent, by hard marching and extraordinary heat", zooals de kolonel Th. Carey aan Lord Arlington rapporteerde ${ }^{5}$ ).

Alonso Lopes de Morla (Ned. I, 26, 31) wordt door De Laet niet met name genoemd ${ }^{6}$ ); Van Walbeeck spreekt van den Gouverneur don Alonso.... (rest onleesbaar), de Spaansche documenten noemen hem Lope Lopez de Morla ${ }^{7}$ ).

Den Heer Pieter Mortamer (Ned. I, D. 72) heeft H. verzuimd in zijn Naamregister op te nemen. Zestien jaar eerder vinden wij een Mortamer als afgevaardigde van de Kamer Zeeland ter Staten Generaal ${ }^{8}$ ); twee en twintig jaar eerder een Moorthamer als directeur te Paolo de Loando in Angola ${ }^{9}$ ).

Kapitein Morus van Jamaica (Ned. II, 40; Jaarv. III, 69) was natuurlijk de boekanier Morris ${ }^{10}$ ).

Kapitein Munnik (Jaarv. III, 70) kan geweest zijn de kapitein De Munnick van den driedaagschen zeeslag, of de brandercommandeur Dirck de Munnick van den slag bij Solebay ${ }^{11}$ ).

Van den zeventiende eeuwschen David Nassy (Ned. I, 102, D.

1) W. I. Gids, 210.

2) Calendar of State Papers, Am. \& W. I., 1681/85, No. 678, XII.

s) Westergaard, Dan. W. I., zie vroeger.

4) W. I. Gids, XVII, 94.

s) Calendar of State Papers, Am. \& W. I., 1661/1668, I.

•) Iaerl. Verh., 433, 435, 438.

?) W. I. Gids, XVII, 199.

s) Doc. .. Slave Trade...., III, The middle colonies, Introd., zie vroeger.

P) Groot Plakaatboek, 5 Juli 1642.

10) Zeer Aenmerkelyke Reysen van Jan Erasmus Reyning, bew. L. C. Vrijman, 156, Amsterdam 1937.

$\left.{ }^{11}\right)$ De Jonge, Gesch. Ned. Zeew., zie vroeger. 
108) is bekend dat hij een geboren Braziliaan was, niet echter of wij in hem te zien hebben een nazaat van den bekenden Joseph Nassy, den Hertog van Naxos, vertrouwensman van den Sultan en correspondent van Willem van Oranje ${ }^{\mathbf{1}}$ ).

Wie de door Mr Jan van Beuningen aangeroepen Nobeling was (Ned. I, 132), heb ik niet vermogen uit te maken.

Jan Jansz. Otzen (Ned. I, 21, 23, 24, D. 20, 37) was volgens de Spaansche gegevens een kleurling. Van Walbeeck kon hem niet gebruiken en vreesde dat zij die ontevreden waren over de resultaten der expeditie hun teleurstelling op hem zouden wreken, waarom hij hem direct naar Patria terug liet gaan. H. zegt niet of de Otsen die in 1636 verzocht hem op Curaçao land toe te wijzen, dezelfde is die de expeditie van 1634 medegemaakt had, maar wij mogen aannemen van wel ${ }^{2}$ ).

Aangaande de verhouding van Jacques Ousiel (Ned. I, D. 28, Ned. II, D. 7) tot de West-Indische Compagnie heb ik niets naders kunnen vinden. Rev. Geo. Edmundson zegt dat Ousiels verslag, uit Nederlandsche archieven, opgenomen is onder stukken welke gediend hebben bij de grensregeling tusschen Venezuela en Britsch Guyana (de voormalige Nederlandsche vestigingen aan de Pomeroon, de Essequibo, de Demerary en de Berbice) ${ }^{3}$ ).

Jansz. Pater (Ned. I, 20) was natuurlijk Adriaen Jansz. Pater, de Edammer, die zoowel in onze Oost- als in onze West-indische geschiedenis bekend is en die ten slotte in de Allerheiligenbaai het leven liet (1631).

Abraham van Pere (Ned. II, 12, 42, D. 18, 21) is de in onze Westindische geschiedenis meest bekende der vele Van Peres (Van Perres, Van de Perres enz.), in onze koloniale, militaire en diplomatieke historie genoemd. Van Abraham kon indertijd een portret gereproduceerd worden, ter gelegenheid der driehonderdjarige herdenking van de vereeniging van Curaçao met Nederland ${ }^{4}$ ) Dat de naam oorspronkelijk Pereira geweest zou zijn, lijkt moei-

1) $\mathrm{Mr}$ H. J. Koenen, Gesch. d. Joden zie vroeger; J. Wolbers, Geschiedenis van Suriname, Amsterdam 1861; Gedenkb. NederlandCuraçao, 69, zie vroeger; Dr J. Denucé, Afrika in de XVIe eeuw, zie vroeger; Mr Izak Prins, De vestiging der Marranen in NoordNederland in de XVIe eeuw, Amsterdam 1927; Dr M. Wolff, De eerste vestiging der Joden te Amsterdam, zie vroeger.

2) W. I. Gids, XVII, 199; Rapport Van Walbeeck, zie vroeger.

3) The Dutch in Western Guiana (Eng. Historical Review, XVI, 1901).

4) Gedenkhoek, zie hooger. 
lijk aan te toonen $\left.{ }^{1}\right)$. Van het schip De Witte Hond, dat op de thuisreis van Rio de Janeiro in de buurt van Spanje door Engelsche kapers genomen werd (reis 1586/1588) was een der reeders Franciscus van de Perrye van Middelburg ${ }^{2}$ ), dus de relatie der Zeeuwsche Van Peres met de vaart op de nieuwe wereld was al een zeer oude. De Laet noemt Abraham van Pere als een der eerste bewindhebbers in de Kamer Zeeland ${ }^{3}$ ).

Jean-Remi Perrin (Ned. I, D. 215) zou zijn reis naar Brazilië niet in het begin der zestiende, maar in het begin der zeventiende eeuw gemaakt hebben $\left.{ }^{4}\right)$.

Van de De Petersens (Ned. I., 105, 117, 147, 151-155, 206, 208, 214 , D. 6,165$)$ is er een directeur generaal ter kuste van Afrika geweest (Jaarv. I, Bijlagen B.).

Wij vinden Ph. de Longvilliers, Seigneur de Poincy (Ned. II, $15,16$, D. $25,26,27)$ van 1639 tot 1653 als gouverneur van Martinique ${ }^{5}$ ). Hij was eigenlijk intendant aller Fransche Westindische eilanden ${ }^{6}$ ) en is vooral betrokken geweest bij de kolonisatie van Saint Christophe, van welk eiland hij in 1651 van de Fransche Westindische compagnie de ,,seigneurie" en de ,propriété foncière" gekocht had, tezamen met die van St. Barthélemy, St. Croix, St. Martin en onderhoorigheden en dat wel namens zijn orde, die van Malta. In 1660 overleed hij te Saint Christophe; een ander ridder van St. Jan volgde hem op; ook de overige Fransche Antillen zijn een tijd lang heerlijkheden der orde geweest ${ }^{7}$ ).

John Pogson, die in 1672, na de Engelsche verovering van Sint Eustatius, aldaar als commandeur optrad, (Ned. II, 38), heette volgens een ander gegeven Pognon $\left.{ }^{8}\right)$.

De Heer van der Poorte (Ned. I, D. 41) was Jean van der Poorten, door De Laet genoemd als bewindhebber in de Kamer van Zeeland ${ }^{9}$ ).

L'Abbé Joseph de la Porte (Ned. I, D. 213, 215) heeft zijn Voyageur françois, waarvan $\mathrm{H}$. alleen een Nederlandsche bewerking geraadpleegd had, natuurlijk in het Fransch geschreven. Het oor-

1) Prins, Marranen, zie vroeger.

2) Häpke, Niederländische Akten etc. (DI II, Anhang I).

s) Iaerl. Verh., 34.

4) W. I. Gids, XVII, 99.

s) Stokvis, Manuel, zie vroeger.

-) Newton, European nations, zie vroeger.

') De Rochefort, Hist. Naturelle et morale des isles Antilles de 1' Amerique, tw. ed., Rotterdam 1665.

8) De Zeeuwsche expeditie naar de West, zie vroeger.

-) Iaerl. Verh., 34. 
spronkelijke werk bestond uit 42 deelen en verscheen in 17651795; De la Porte zelf (1713-1779) heeft er slechts een gedeelte van geschreven, naar aangenomen wordt de eerste zes en twintig deelen ${ }^{1}$ ).

Pottey (Ned. I, 179, D. 105, 122, 165) komt ook elders voor; A(ldert) Pottey was in 1738 en ook in 1743, secretaris van Curaçao (Jaarv. I, Bijlagen D. en G.). Jan Potey was reeds heel in het begin der zeventiende eeuw een reeder op West Indië ${ }^{2}$ ). In 1673 was er een luitenant Pottey in Suriname ${ }^{3}$ ).

(Wordt vervolgd).

1) Nouv. Biogr. gén.,

2) W. I. Gids, XVIII, 217

s) De Zeeuwsche expeditie naar de West, zie vroeger. 